\title{
LAS RELACIONES HORIZONTALES \\ DE COLABORACIÓN ENTRE COMUNIDADES AUTÓNOMAS: \\ MARCO JURÍDICO, \\ FUNCIONAMIENTO \\ Y RENDIMIENTO
}

M. ${ }^{a}$ JOSEFA RIDAURA MARTÍNEZ 
SUMARIO

I. INTRODUCCIÓN. II. EL LABORIOSO ARRANQUE DE LAS RELACIONES HORIZONTALES O INTERCOMUNITARIAS. II. SISTEMATIZACIÓN DEL MARCO NORMATIVO VIGENTE. 1. Marco Constitucional. 2. Marco Estatutario. III. EVIDENCIA DE LA PRÁCTICA EMPÍRICA EN MATERIA DE COLABORACIÓN HORIZONTAL ENTRE CC.AA. 1. Etapas en la colaboración horizontal. 2. La materialización de la colaboración entre CC.AA. 3. La constitución de nuevos instrumentos de colaboración. 


\title{
LAS RELACIONES HORIZONTALES \\ DE COLABORACIÓN ENTRE COMUNIDADES AUTÓNOMAS: MARCO JURÍDICO, FUNCIONAMIENTO Y RENDIMIENTO
}

\author{
M. JOSEFA RIDAURA MARTÍNEZ \\ Profesora Titular de Derecho Constitucional \\ Universidad de Valencia
}

\section{INTRODUCCIÓN ${ }^{1}$}

Una particularidad de los Estados descentralizados políticamente es la existencia de sólidos y eficaces instrumentos de colaboración horizontal²; habiéndo-

1 Este artículo se enmarca en el Proyecto de Investigación Ref. CSO2009-14381-C03-03, Financiado por el Plan Nacional de Investigación Científica, Desarrollo e Innovación Tecnológica 2010-2012.

2 Podemos encontrar ejemplos de Estados de estructura compuesta en los que los que diversos instrumentos de colaboración entre entes descentralizados están fuertemente arraigados. Véase, por ejemplo, la Constitución Suiza (1999), cuyo artículo 48 contempla los Acuerdos entre Cantones, así como la posibilidad de que éstos lleven a cabo de manera conjunta tareas de interés regional; funcionando, además, una Conferencia de los Gobiernos cantonales, creada en 1993. En Canadá, Foundation Agreement 2003 establece el Council of the Federation como órgano de colaboración horizontal. En Italia la Conferencia de los Presidentes de las Regiones, hoy en día Conferencia de las Regiones y Provincias Autónomas, funciona con reuniones periódicas, y lo hacen previamente a la Conferencia Estado-Regiones para discutir los puntos a tratar en esta última. En Alemania, las Conferencias Sectoriales entre los Lander y la Conferencia de Primeros Ministros son 
se constatado empíricamente las ventajas que éstos reportan para fortalecer el autogobierno de los entes descentralizados; apareciendo así como un freno ante las tendencias recentralizadoras ${ }^{3}$. Además, dichos instrumentos, permitiendo una mayor integración y participación de estos entes en las decisiones generales ${ }^{4}$, contribuyen a favorecer la gestión más eficaz de los servicios públicos, redundando en una mayor calidad de los mismos para el ciudadano.

Sin embargo, en España, hasta hace bien poco, se ha hecho un uso escaso de los instrumentos horizontales; como consecuencia de que las relaciones de colaboración entre Comunidades Autónomas han sido deficitarias; llegando, incluso, a calificarse de «desoladoras» 0 «raquíticas» ${ }^{6}$.

En los últimos años, no obstante, hemos asistido a una generalización de estos instrumentos de colaboración horizontal; consecuencia de la afirmación de la estructura territorial descentralizada de nuestro Estado, que ha permitido dotar de mayor normalidad a las relaciones intercomunitarias, en cuyo marco este tipo de instrumentos son imprescindibles. Relaciones, que, al igual que las verticales entre Estado y CC.AA., se enmarcan en los principios de colaboración, solidaridad y lealtad como principios de ordenación del Estado Autonómico (SSTC 201/1988, de 27 de octubre, 96/1990, de 24 de mayo); y que pilotan sobre la solidaridad en su manifestación de comportamiento leal entre los poderes territoriales del Estado. Y, particularmente, el artículo 4 de la Ley 30/1992 de Régimen Jurídico de las Administraciones Públicas, que establece como principio de actuación y de relación de las Administraciones Públicas el de Lealtad Institucional como una manifestación del principio de Lealtad constitucional, se proyecta, asimismo,

instrumentos esenciales de colaboración horizontal. Para un estudio más detallado de las experiencias comparadas vid. GARCÍA MORALES, M. J. (1998). Convenios de Colaboración en los sistemas federales europeos: Estudio comparativo de Alemania, Suiza, Austria y Bélgica, Mac-Graw-Hill, Madrid.

3 SAINT-OUEN, F. (2005). «Suiza: un ejemplo federalista de descentralización territorial», Fundación Manuel Giménez Abad, p. 15.

4 AJA, E. y GARCÍA MORALES, M.J. (2000). «Las Relaciones entre Comunidades Autónomas: problemas y perspectivas», Informe Comunidades Autónomas 2000, Instituto de Derecho Público, Barcelona, pp. 647-448. La existencia en la mayoría de los países de nuestro entorno de instancias de colaboración horizontal (Conferencia de Ministros en Alemania, Conferencia de Presidentes en Suiza, o Conferencia de Gobiernos Cantonales en Suiza) permiten la adopción de posiciones comunes frente a la Federación favoreciendo con ello la posición de los entes descentralizados en las negociaciones y decisiones generales. ALBERTI ROVIRA, E.(1994). «Los Convenios entre Comunidades Autónomas», Documentación Administrativa, núm. 240, p. 109.

5 CONTRERAS, M. (2008) «Las relaciones entre las Comunidades Autónomas: un reto pendiente en el Estado Autonómico», en II Jornadas sobre los Estatutos de Autonomía, Dirección General de Desarrollo Autonómico (Vicepresidencia del Gobierno de Aragón).

6 IBÁÑEZ BUIL, P. (1997). «Los convenios entre Comunidades Autónomas», REAL, núms. 274-275, p. 492. 
sobre las Administraciones autonómicas; marco en el que se desarrollan las relaciones intergubernamentales horizontales objeto de estudio.

Este trabajo tiene como objeto el estudio las relaciones de colaboración horizontales entre Comunidades Autónomas en el marco de nuestro Estado descentralizado; centrándonos en el análisis de la ordenación jurídica y, señaladamente, del rendimiento de los instrumentos a través de los que se canaliza dicha colaboración.

Para ello analizaremos el marco normativo de las relaciones entre Comunidades Autónomas, tanto constitucional como estatutario, en cuanto que es éste el que habilita para el desarrollo de dichas relaciones, y, por tanto, determina la práctica de los convenios y acuerdos que se han venido celebrando entre las Comunidades. Esta primera aproximación, que tiene un carácter más descriptivo que analítico-explicativo, nos ayudará a desbrozar la compleja realidad de los convenios y de los acuerdos de colaboración horizontales.

En primer lugar, examinamos las causas de la compleja implantación de los instrumentos de colaboración entre las Comunidades Autónomas. En el siguiente epígrafe procedemos al estudio de su ordenación jurídica, como marco de obligada referencia para la realización y validez de dichos instrumentos. Y, en el último epígrafe, nos centramos en el funcionamiento y rendimiento de los instrumentos de colaboración horizontal.

\section{EL LABORIOSO ARRANQUE DE LAS RELACIONES HORIZONTALES O INTECOMUNITARIAS}

El inicial déficit de colaboración horizontal, manifestado en el escaso número de convenios suscritos ${ }^{7}$, que caracterizó los albores del desarrollo del Estado Autonómico, puede explicarse desde vertientes de naturaleza tanto jurídica, como política. Destacando, entre estas últimas, la propia singularidad de nuestro proceso de descentralización política; caracterizado, desde un principio, por situar el centro de gravedad de las Relaciones Intergubernamentales en las relaciones verticales $^{8}$; planteadas, a su vez, en gran medida, en clave de recelo y

Ese escaso «número de convenios horizontales suscritos es, sin duda, el dato más elocuente de la precaria situación de la colaboración interautonómica»' GARCÍA MORALES, M. ${ }^{a}$ J. (2006). «Las Relaciones Intergubernamentales en el Estado Autonómico: estado de la cuestión y problemas pendientes», en GARCÍA MORALES, M. ${ }^{a}$ J., MONTILLA MARTOS, J. A. Y ARBÓS MARÍN, X., Las Relaciones Intergubernamentales en el Estado Autonómico, Madrid, Centro de Estudios Políticos y Constitucionales, p. 15.

8 Que, pese a estar silenciadas en el texto constitucional, fueron avaladas desde el principio por la doctrina constitucional, al considerar que dichos instrumentos son expresión del principio 
desconfianza por parte de las Comunidades Autónomas ante el Gobierno central ${ }^{9}$. Y es que, las Comunidades Autónomas estuvieron, hasta hace bien poco, más orientadas a ampliar sus competencias, a conseguir financiación para desarrollarlas, así como a articular la estructura político-administrativa que permitiera su actuación; en cuyo marco las relaciones intercomunitarias, así como los mecanismos de colaboración intracomunitarios que las facilitan, quedaban en un segundo plano.

Otro elemento que ha contribuido a la precariedad de las relaciones horizontales ha sido la búsqueda de espacios sobre los que centrar la colaboración; en este sentido, puede decirse que muchos ámbitos en los que, realmente, se puede colaborar para la gestión y prestación de servicios dependía de la asunción de competencias por parte de las CC.AA., por lo que la heterogeneidad del mapa competencial ha dificultado las relaciones entre ellas.

de colaboración que «no necesita justificarse en preceptos constitucionales o estatutarios concretos», puesto que las «técnicas de cooperación y colaboración son consustanciales a la estructura compuesta del Estado de las Autonomías» (SSTC 13/1992, de 6 de febrero; 132/1996, de 22 de julio, entre otras). Sin embargo, la ausencia de regulación constitucional no es un fenómeno aislado, ya que como advirtió en su día SANTOLAYA MACHETTI, P. (1984) «el estudio de la experiencia de los países descentralizados muestra que los mecanismos de cooperación se han desarrollado, en la mayor parte de los casos, al margen de sus textos constitucionales, de forma que se puede concluir que lo importante es no tanto que los textos los prevean cuanto al menos que no impidan el libre desarrollo praeter constitutionis de los mismos», "Entorno al Principio de Cooperación», Revista de Derecho Político, núm. 21, p. 86.

Vid. Sobre el desarrollo y consolidación de los instrumentos de colaboración vertical ALBERTI ROVIRA, E. (1985): «Las relaciones de colaboración entre el Estado y las Comunidades Autónomas» en Revista Española de Derecho Constitucional, núm. 14, pp. 135-180. FERNÁNDEZ ALLES, J.J. (2004) «Bases para una teoría constitucional española sobre las relaciones intergubernamentales», REDC, núm. 72, pág. 52 y ss. GARCÍA MORALES, M. ${ }^{2}$ J., MONTILLA MARTOS, J.A. y ARBÓS MARÍN, X., Las Relaciones Intergubernamentales en el Estado Autonómico, Centro de Estudios Políticos y Constitucionales, Madrid, 2006; GONZÁLEZ AYALA, M. ${ }^{a}$ D. (2009). »Las relaciones intergubernamentales en el nuevo marco de las reformas estatutarias: La diferente conciliación de la bilateralidad-multilateralidad en las relaciones Estado-Comunidad Autónoma», InDret, núm. 1. RIDAURA MARTÍNEZ, M. J. (2009). Relaciones Intergubernamentales Estado-Comunidades Autónomas, Tirant lo Blanch, Valencia, 2009; RUIZ GONZÁLEZ, J.G. (2012). «La cooperación intergubernamental en el estado autonómico: situación y perspectivas», REAF, núm. 15, pp. 287-328. TAJADURA TEJADA, J. (2010). El principio de cooperación en el Estado Autonómico, Comares, Granada.

9 Lo que no causa extrañeza, ya que se salía de un fuerte centralismo y, por tanto, como reacción al mismo, como expresó AJA, «las CC.AA. comenzaron su autogobierno mirando sólo su propio ombligo», AJA, E. (2003). El Estado autonómico. Federalismo y hechos diferenciales, Madrid, Alianza Editorial, p. 138. 
En definitiva, el afianzamiento del Estado Autonómico ha sido el detonante para que las Comunidades Autónomas advirtieran, en el ejercicio normal de su desarrollo competencial, la necesidad de la colaboración entre ellas, mostrándose en este marco imprescindibles los instrumentos de colaboración horizontales.

No obstante, otras de las causas que ha dificultado y dificultan entre determinadas CC.AA. la generalización de este tipo de instrumentos jurídicos, ha sido el recelo político existente entre algunas Comunidades limítrofes, en cuyo ámbito se plantean cuestiones de anexión política, cultural y lingüística.

En otros casos, la emulación del Estado por parte de algunas CC.AA. les ha conducido a dirigir su mirada más hacía las relaciones externas que hacia las internas; lo que se pone de manifiesto, tanto en la práctica, como en el detalle y la profundidad que se dedica a esta dimensión externa comunitaria en la mayoría de las recientes reformas estatutarias ${ }^{10}$. Detalle que contrasta con la escasa atención que se ha prestado a «las mejoras técnicas que requería la colaboración horizontal ${ }^{11}$; de ahí que se haya llegado a calificar certeramente a estas recientes reformas estatutarias, en este ámbito concreto, como un «reto secundario» ${ }^{12}$.

Se suele comparar el alto número de convenios verticales entre Estado y CC.AA. con las escasas cifras de convenios horizontales, para remarcar la poca voluntad de colaboración de estas últimas. Es cierto que en ambos casos nos encontramos con instrumentos que se caracterizan por su voluntariedad. Pero, esta comparación cuantitativa, desde nuestro punto de vista, no es completamente reveladora del escaso espíritu de colaboración comunitario, ya que la práctica que ha rodeado a los convenios verticales ha sido bien distinta de la que puede predicarse de los convenios horizontales. En efecto, aquellos han sido utilizados, tanto para articular las relaciones entre órganos centrales del Estado y las CC.AA., como para canalizar los traspasos de competencias. Además, con posterioridad, estos convenios se han convertido en instrumento de territorialización de subvenciones acordadas en Conferencias Sectoriales ${ }^{13}$. Ámbitos de

10 Vid. Con mayor detalle, ELÍAS MÉNDEZ. C. (2009). «Principales rasgos de las reformas estatutarias: ¿Hacia un Estado autonómico cooperativo?, Revista Valenciana D'Estudis Autonòmics, núm. 52, pp. 258-283.

11 GARCÍA MORALES, M. ${ }^{a}$ J. (2009). «Los nuevos Estatutos de Autonomía y las relaciones de colaboración: un nuevo escenario, ¿una nueva etapa?», en Las relaciones de colaboración en los nuevos Estatutos de Autonomía en Revista Jurídica de Castilla y León, núm. 19, p. 377.

12 SALAZAR BENÍTEZ, O. (2006). «Las relaciones de cooperación entre las Comunidades Autónomas, Un reto secundario en las reformas estatutarias», en RUIZ-RICO RUIZ, G., (coord.), La Reforma de los Estatutos de Autonomía, Valencia, Tirant lo Blanch, p. 849.

13 Conviene advertir, que también en este ámbito se ha puesto de manifiesto la insuficiente regulación legal de los Convenios, por lo que el Pleno del Tribunal de Cuentas planteó el 30 de 
actuación que no se dan en el marco de las relaciones entre Comunidades Autónomas, y que han disparado las cifras de convenios verticales respecto de los horizontales.

Desde una vertiente jurídica, las exigencias constitucionales y estatutarias son, principalmente, las que han dificultado la expansión de las relaciones horizontales, ya que la excesiva rigidez del marco normativo propició, originariamente, un escaso uso de los convenios intracomunitarios.

Pese a todas estas dificultades, la necesidad de colaborar entre las CC.AA. en el marco de un Estado descentralizado consolidado ha posibilitado sortear los obstáculos existentes, generalizándose como instrumentos imprescindibles para el cabal desarrollo de nuestro Estado autonómico. Y todo ello se ha materializado, de modo paulatino, en el tejido de una serie de relaciones entre las Comunidades Autónomas, particularmente, a través de lo que se ha venido denominando la Colaboración Sumergida ${ }^{14}$, o de instrumentos de Derecho privado ${ }^{15}$; de ahí que pueda sostener que, en la realidad, ha existido «más colaboración horizontal de la que se ve» ${ }^{16}$. Por lo que, pese a las dificultades en el ensamblaje de nuestro modelo de organización territorial, pese a la rigidez normativa, así como, pese a la precariedad de los cauces institucionales a través de los que articular dicha colaboración, la aptitud de dichos instrumentos jurídicos para vehiculizar el pleno ejercicio de las competencias autonómicas explica la generalización de dichos instrumentos.

Consecuentemente, en los últimos años, a la par que las relaciones de carácter horizontal entre las Comunidades Autónomas han ido cobrando una especial relevancia, no sólo se han consolidado los instrumentos horizontales previstos en el ordenamiento jurídico, sino que, además, se han articulado nuevos instrumentos de relación intercomunitaria, que han permitido obtener unos resultados

noviembre de 2010, una Moción destinada a las Cortes Generales, proponiendo la configuración de un marco legal adecuado y suficiente para el empleo del convenio de colaboración por las Administraciones Públicas y la adopción de las medidas necesarias para un uso eficiente de los recursos públicos que se canalizan por esta vía.

14 TORNOS MAS, J. (2007). Informe de Comunidades Autónomas 2006, Barcelona, Instituto de Derecho Público, pp. 30 y ss.

15 GARCÍA MORALES, M. J. (2009). «La colaboración a examen: Retos y riesgos de las relaciones intergubernamentales en el Estado autonómico», Revista Española de Derecho Constitucional, núm. 86, p.79

16 COLINO CÁMARA, C. (2011) «Federalismo Horizontal en el Estado Autonómico. La evolución de los mecanismos de cooperación horizontal en España», en Cuadernos Manuel Giménez Abad, núm. 2, p. 45. 
cualitativa y cuantitativamente mayores; permitiendo consolidar a dichos instrumentos como herramientas jurídicas imprescindibles en nuestro Estado autonómico.

\section{SISTEMATIZACIÓN DEL MARCO NORMATIVO VIGENTE}

\section{Marco Constitucional}

El artículo 145.2 de la Constitución dispone que las CC.AA. pueden celebrar, por un lado, Convenios para la gestión y prestación de servicios propios de las mismas; en este caso, según el tenor literal del precepto, corresponde a los Estatutos de Autonomía la regulación de los supuestos, requisitos y términos de su celebración, así como el carácter y los efectos de su comunicación a las Cortes Generales. Por otro, pueden adoptar Acuerdos de cooperación, para los que se requiere la previa autorización de las Cortes Generales ${ }^{17}$. Este precepto, de acuerdo con la doctrina constitucional, no habilita a las Comunidades para establecer convenios entre ellas, sino que, «supuesta esa capacidad, delimita por su contenido los requisitos a que ha de atenerse la regulación de esta materia en los Estatutos y establece el control por las Cortes Generales de los acuerdos o convenios de cooperación» (STC 44/ 1986, de 17 de abril) ${ }^{18}$.

Esta regulación viene precedida de la prohibición de federación de Comunidades Autónomas (artículo 145.1); apartado que acaparó la mayor atención en los debates constituyentes, ante los temores de que ello pudiera quebrar la unidad del Estado ${ }^{19}$.

17 Vid. sobre la problemática que plantea la intervención de las Cortes Generales en este ámbito la analiza pormenorizadamente GUTIÉRREZ VICEN, C. (2000). «La Intervención de las Cortes Generales en la celebración de convenios entre Comunidades Autónomas: la aparición de nuevos problemas», Corts, Anuario de Derecho Parlamentario, núm. 9, pp. 283 y ss.

18 Sentencia que resuélvela impugnación vía artículo 161.2 CE interpuesta por el Presidente del Gobierno contra Resolución del Presidente de la Generalidad de Cataluña por la que aprueba el Convenio, suscrito con el Presidente del Consejo Regional de Murcia sobre participación y cooperación en cuantas actuaciones afecten a las aspiraciones y necesidades comunes a ambas colectividades; siendo Murcia entonces ente preautonómico.

19 Esta prohibición aparece también en otros países de estructura federal o compleja: artículo 7 de la Constitución de Suiza; artículo 1, sección 10, apartados 1 y 3 de la Constitución de los Estados Unidos de América; artículo 117 de la Constitución de México de 1917; artículo 108 de la Constitución Argentina de 1853. Sinopsis del Artículo 145 CE realizada por BACIGALUPO SAGESSE, M., en Portal de la Constitución, Congreso de los Diputados (http://congreso.es). 
La redacción constitucional del artículo $145.2^{20}$ plantea serios inconvenientes $^{21}$ : en primer lugar, el precepto no aclara las actuaciones que deben recibir la calificación de convenio o de acuerdo, y, por ende, cuando es o no necesaria la autorización de las Cortes Generales ${ }^{22}$. Como se podrá apreciar a continuación, las consecuencias de esta indeterminación conceptual son relevantes, ya que en atención a la calificación que reciban, el artículo 145.2 CE dispone un régimen distinto en orden a la intervención de las Cortes Generales: en el caso de los convenios es suficiente con su comunicación; en el caso de los acuerdos es necesaria su aprobación por las Cámaras; diferenciación que tampoco los Estatutos de Autonomía han logrado clarificar, como tendremos ocasión de ver a continuación.

En segundo lugar, el principal escollo en la ordenación jurídica de los convenios horizontales se produce en la remisión que el texto constitucional hace a los Estatutos de Autonomía para la determinación de los supuestos, requisitos y términos en que éstos se puedan celebrar, así como el carácter y los efectos de la correspondiente comunicación a las Cortes Generales. De hecho, es precisamente en este terreno estatuario donde mayores obstáculos se han opuesto a la realización efectiva de la práctica convencional horizontal; por lo que puede afirmarse que las mayores dificultades no derivan de la letra de la Constitución, sino de los propios Estatutos de Autonomía. Y es que, el texto constitucional permite que sean los Estatutos los que ordenen jurídicamente su actividad convencional; sin embargo, existe acuerdo doctrinal unánime al entender que el desarrollo que los Estatutos de Autonomía han efectuado del mandato constitucional ha contribuido bien poco a dotar de un marco homogéneo y apropiado a la actividad

20 Un estudio en profundidad del iter parlamentario de este precepto lo realizan GONZÁLEZ GARCÍA, I. (2006) «La prohibición de federación entre territorios autónomos en el constitucionalismo español», en Derecho constitucional para el siglo XXI: Actas del VIII Congreso Iberoamericano de Derecho Constitucional /coord. por CARRASCO DURÁN, M., PÉREZ ROYO, F.J., URÍAS MARTÍNEZ,:, TEROL BECERRA, M., Vol. 2, 2006, pp. 4459-4471. TAJADURA TEJADA, J. (2010). «Los Convenios de Cooperación entre Comunidades autónomas: Marco normativo y propuestas de reforma». REAF, núm. 11, pp. 211 y ss. SÁNCHEZ NAVARRO, A.J. (1998), «El artículo 145», en Comentarios a la Constitución española, Madrid, Edersa.

21 En palabras de ALBERTI ROVIRA (1994), el texto constitucional aborda el tema «desde una perspectiva meramente instrumental, de modo fragmentario y con muchos problemas de interpretación del régimen previsto». p. 110.

22 RUIZ GONZÁLEZ, J. G. (2012). «La cooperación intergubernamental en el estado autonómico: situación y perspectivas», REAF, 15 , pp. 310 y ss. Trabajo en el que analiza pormenorizadamente todo el entramado de los instrumentos de colaboración, tanto verticales, como horizontales; resaltando los últimos avances en este campo. 
convencional interautonómica ${ }^{23}$. En efecto, dicha remisión constitucional a los textos comunitarios no ha sido adecuadamente desarrollada por los Estatutos de Autonomía, ya que éstos, como en su día puso de manifiesto SANTOLAYA, han operado «una auténtica dejación de la titularidad estatutaria de definición del ámbito de los convenios —y reflejamente del de los «acuerdos»—, en manos de las Cortes Generales e incluso en algunos casos en manos de una sola de las Cámaras» ${ }^{24}$.

\section{Marco Estatutario}

Los Estatutos de Autonomía, al cumplir con el mandato constitucional, en lugar de proceder a una ordenación homogénea y coherente de dichas exigencias constitucionales en aras de facilitar una colaboración convencional más fluida entre las Comunidades Autónomas, plantean importantes trabas, que podríamos agrupar en tres órdenes:

1. En primer lugar, los Estatutos de Autonomía no han contribuido a ofrecer un criterio material de delimitación entre los convenios de colaboración y los acuerdos de cooperación; el único criterio utilizado, en idénticos términos que el texto constitucional, es vincular los convenios con la gestión y prestación de servicios propios en materias de su competencia, incluso en algunos casos limitándolo a las exclusivas ${ }^{25}$; erigiéndose, así, una correspondencia entre servicios propios y competencias exclusivas. Dicha vinculación, además

23 Vid. GONZÁLEZ GARCÍA, I. (2009). «Un distingo constitucionalmente relevante: los convenios de colaboración vs. Acuerdos de cooperación entre Comunidades Autónomas», Revista de Estudios Políticos, núm. 145, pp. 97-118. El autor analiza con mayor detalle el desarrollo del artículo 145 de la CE en los distintos Estatuto de Autonomía. Además, Alberti, ha calificado dicha remisión constitucional como incorrecta, ya que atribuye a normas particulares (EA) «la determinación de los efectos que debe surtir un acto de control estatal», ALBERTI ROVIRA, E. (1994). «Los convenios entre Comunidades Autónomas», Documentación Administrativa, núm. 240/1994, p. 125 .

24 «Entorno al Principio de Cooperación», Revista de Derecho Político, núm. 21, pp. 105-106.

25 El tema ha sido objeto de un amplio debate doctrinal, vid. SANTOLAYA MACHETTI, P. (1984). Descentralización y cooperación, Madrid, IEAL; SÁNCHEZ NAVARRO, A. (1999). «Artículo 145. Convenios entre Comunidades Autónomas», en ALZAGA VILLAAMIL, O. (Dir.), Comentarios a la Constitución Española de 1978, tomo XI. Madrid, Edersa; TAJADURA TEJADA, J. (1996). «El artículo 145 de la Constitución española: los convenios y acuerdos de cooperación entre las CC.AA.», Revista Jurídica de Navarra, núm. 21, pp.; MENÉNDEZ REXACH, A. (1982). Los Convenios entre las Comunidades Autónomas, Madrid, Instituto de Estudios de Administración Local. 
de no clarificar conceptualmente los convenios de colaboración, y, por tanto, no distinguirlos de los acuerdos, es poco conveniente, ya que, aun siendo evidente que las Comunidades Autónomas sólo pueden celebrar convenios en ámbitos en los que tienen competencias, puede darse el caso de que la gestión o prestación de servicios no se corresponda con el ámbito material sobre el que la Comunidad Autónoma tiene sólo competencias exclusivas ${ }^{26}$; por lo que parece más acertado extender la posibilidad de celebrar convenios en las materias en las que tengan competencias, sin ceñirlas sólo a las exclusivas. En esta dirección, la mayoría de las CC.AA. han aprovechado las recientes reformas estatutarias para despojarse de esta cláusula ${ }^{27}$ : es el caso del Estatuto Aragonés ${ }^{28}$ (artículo 91.2); del Estatuto de Andalucía ${ }^{29}$ (artículo 226); del Estatuto Balear ${ }^{30}$ (artículo 118); del Estatuto Catalán ${ }^{31}$ (artículo 178) y del Estatuto de Extremadura ${ }^{32}$ (artículo 68); todos ellos se refieren a las competencias comunitarias, pero sin limitarlas a las exclusivas. La excepción la constituyen el Estatuto de Autonomía de la Comunidad Valenciana (artículo 59) y la más reciente reforma de la Ley de Reintegración y Amejoramiento del Régimen Foral de Navarra ${ }^{33}$ (artículo 70), que siguen contemplando la celebración de Convenios con las Comunidades Autónomas para la gestión y prestación de servicios propios sin romper la conexión de estos con la exclusividad competencial.

Ciertamente, ni el criterio formal que se desprende del artículo 145 de la Constitución, en atención a la intervención de las Cortes Generales, ni tampoco

26 Vid. en este sentido, CARMONA CONTRERAS, A. (2004). «¿Hacia una nueva dimensión de las relaciones intergubernamentales», Revista de Derecho Constitucional Europeo, núm. 1, p. 96.

27 Esta es la tesis mantenida por J. TAJADURA TEJADA, que compartimos, quien acertadamente advierte que, puesto que el artículo 145 de la CE se limita a exigir el texto que las competencias sean «propias» hay que entender por tales tanto las exclusivas como las compartidas o concurrentes, TAJADURA TEJADA, J. (2010). «Los convenios de cooperación entre Comunidades Autónomas: marco normativo y propuestas de reforma», REAF, núm. 11, pp. 223 y 241.

28 Ley Orgánica 5/2007, de 20 de abril, de reforma del Estatuto de Autonomía. Posteriormente, la Ley 1/2011, de 10 de febrero, de convenios de la Comunidad Autónoma de Aragón distingue los entre los Convenios de colaboración, que tendrán por objeto la gestión y prestación de servicios propios, derivados de las competencias autonómicas (Artículo 17. 1.) de los Acuerdos de cooperación (artículo 18.1) que los concibe como relativos a actuaciones que no sean objeto de los convenios.

29 Ley Orgánica 2/2007, de 19 de marzo, de reforma del Estatuto de Autonomía para Andalucía.

30 Ley Orgánica 1/2007, de 28 de febrero, de reforma del Estatuto de Autonomía de las Islas Baleares.

31 Ley Orgánica 6/2006, de 19 de julio, de reforma del Estatuto de Autonomía de Cataluña.

32 Ley Orgánica 1/2011, de 28 de enero, de reforma del Estatuto de Autonomía de la Comunidad Autónoma de Extremadura

33 Reforma aprobada mediante Ley Orgánica 7/2010, de 27 de octubre. 
el carácter de la competencia al que se refieren algunos Estatutos de Autonomía, parecen explicar las diferencias entre Convenios de colaboración y Acuerdos de cooperación.

Consideramos que tanto los Convenios de Colaboración como los Acuerdos de Cooperación son manifestaciones de la voluntad política de los Ejecutivos autonómicos; por tanto, son acuerdos políticos que, una vez adoptados, son jurídicamente vinculantes ${ }^{34}$. Pero, el objeto sobre el que recaen es distinto: en el caso de los convenios, el elemento determinante es el carácter ejecutivo o administrativo de la actividad sobre la que se proyectan los compromisos contraídos ${ }^{35}$; mientras que el objeto de los acuerdos trasciende dicho carácter. En esta dirección, más recientemente, la Ley Orgánica 1/2011, de 28 de enero, de reforma del Estatuto de Autonomía de la Comunidad Autónoma de Extremadura dispone la facultad de la Junta para proponer, negociar y formalizar con otros Gobiernos autonómicos convenios «para la planificación, gestión y prestación de servicios de carácter administrativo o ejecutivo en todas las materias de su competencia» (artículo 65). Distinguiéndolos de los acuerdos de cooperación que, a propuesta de la Junta, la Comunidad Autónoma pueda formalizar con otras Comunidades Autónomas en el ámbito de sus respectivas competencias para el ejercicio conjunto de funciones normativas, institucionales y politicas diferentes de las puramente reglamentarias, ejecutivas o administrativas ...» (artículo 66). Como podrá apreciarse, es el texto que con mayor detalle y acierto regula los dos instrumentos de colaboración, al establecer una clara delimitación material entre ellos ${ }^{36}$.

34 Lo que conduce a ALBERTI ROVIRA, E. (1994) a afirmar que el convenio tiene la naturaleza de un contrato, si bien de características especiales por razón de su objeto y de las partes intervinientes, p. 114.

35 ALBERTI ROVIRA, E. (1994), p. 120; IBÁÑEZ BUIL, P. (1997). «Los convenios entre Comunidades Autónomas», REAL, núms. 274-275, p. 495. El objeto del Convenio «apunta a facultades ejecutivas de ejercicio conjunto sobre materias acerca de las que las Comunidades Autónomas tienen competencias», MENEZ REXACH, A. Y SOLOZABAL ECHEVARRIA, J.J. (2011). El Principio de Colaboración en el Estado Autonómico, Fundación Manuel Giménez Abad, Zaragoza, pp. 21-22. Por su parte, RAZQUIN LIZARRAGA, M. M. a (1990), entiende que «la diferencia conceptual entre ambos tipos se halla en que los convenios van dirigidos única y exclusivamente a la prestación de servicios en materias de competencia exclusiva o no; en cambio, los acuerdos de cooperación exceden el ámbito de la prestación de los servicios y, sin llegar al extremo prohibido de la federación, pueden cumplir funciones de todo tipo, incluso de carácter político», «Las relaciones de la Comunidad Foral de Navarra con las Comunidades Autónomas: convenios y acuerdos de cooperación», Revista Jurídica de Navarra, núm. 10, pp. 25.

36 Previamente, la Ley 26/2010, de 3 de agosto, de Régimen Jurídico y de Procedimiento de las Administraciones Públicas de Cataluña, define —en su artículo 108 - los convenios como «todo acuerdo sujeto al derecho público, del que se derivan obligaciones jurídicas directas para las 
2. En segundo lugar, muchos Estatutos de Autonomía sumaron como requisito interno la aprobación de los convenios de colaboración por sus respectivos Parlamentos ${ }^{37}$; requisito que no exige la Constitución y que tiene difícil explicación en este tipo de instrumentos convencionales. En este caso podríamos agrupar dicha ordenación estatutaria del siguiente modo:

a) Estatutos que limitan la intervención parlamentaria a los convenios que afecten a facultades legislativas de la Comunidad Autónoma; en los demás casos, el Gobierno debe informar al Parlamento de la suscripción en el plazo de un mes a contar desde el día de la firma (artículo 178 EA de Cataluña ${ }^{38}$ ).

b) Estatutos que prevén que los convenios para la planificación, gestión y prestación de servicios de carácter administrativo o ejecutivo sean comunicados a la Asamblea para el mero examen de una colisión con sus competencias estatutarias (el recién reformado Estatuto Extremeño en su artículo 65.3).

c) Estatutos que han suprimido la intervención parlamentaria autonómica: el de Aragón ${ }^{39}$, que sólo prevé la mera comunicación (artículo 91.2), y el Estatuto Balear (artículo 118 ${ }^{40}$.

partes»; distinguiéndolos de los Protocolos, a los que define como «los instrumentos que se limitan a establecer acuerdos generales de carácter programático o declarativo, sin eficacia obligatoria directa y cuyo cumplimiento no es susceptible de ser exigido jurídicamente».

37 CANO BUESO, J. (1990). «El papel de los Parlamentos autonómicos en el sistema de cooperación interterritorial», en CANO BUESO, J. (ed.), Comunidades Autónomas e instrumentos de cooperación interterritorial, Tecnos, Madrid pp. 71-102.

38 Un estudio más detallado en MONTILLA MARTOS, J.A. (2005). «Más sobre el tema: apuntes sobre colaboración y participación en el estado autonómico. a propósito de la propuesta de reforma del estatuto de Cataluña», REAF núm. 1, pp. 145-146. CORRETJA TORRENS, M., PÉREZ VELASCO, M.M. (2009). «La colaboración en Cataluña «, Monográfico sobre Las relaciones de colaboración en los nuevos Estatutos de Autonomía, Revista Jurídica de Castilla y León, núm. 19, pp. 68 y ss.

39 DE PEDRO BONET, X. (2009). «La colaboración en Aragón», Monográfico sobre Las relaciones de colaboración en los nuevos Estatutos de Autonomía en Revista Jurídica de Castilla y León, núm. 19, pp. Más recientemente, se ha aprobado la Ley 1/2011, de 10 de febrero, de Convenios de la Comunidad Autónoma de Aragón, así como el Decreto 57/2012, de 7 de marzo, del Gobierno de Aragón, por el que se regula el Registro General de Convenios de la Comunidad Autónoma de Aragón. La primera de ellas regula el ámbito de actuación de los Convenios con otras CC.AA. con la finalidad de fijar políticas comunes y tratar de asuntos de interés recíproco en beneficio de sus ciudadanos. Contempla las relaciones multilaterales de colaboración con otras Comunidades Autónomas para facilitar el ejercicio eficaz de sus competencias, especialmente cuando sus efectos tengan un alcance territorial supra autonómico (artículo 14).

40 Medida que ha sido valorada positivamente por CALAFELL, al considerar que «La cooperación — tanto vertical como horizontal— se produce esencialmente entre órganos ejecutivos y, en el aspecto procedimental, se distingue por la agilidad en la tramitación de los instrumentos en que se concreta. Por ello, un desproporcionado protagonismo de los Parlamentos puede mermar 
d) Estatutos que mantienen la necesaria intervención parlamentaria, aun con diversos regímenes: en el caso de la Rioja se requiere previa a su formalización, la aprobación y autorización del Parlamento (artículo 14) ${ }^{41}$. En los casos de Asturias (artículo 24.7) y Murcia (25.7) se requiere la previa autorización de sus respectivas Cámaras. En el de la Comunidad Valenciana (59) ${ }^{42}$, Canarias (38) y Castilla-La Mancha (9.2) se habla de previa aprobación por sus Parlamentos. Finalmente, Madrid (artículo 14) y Castilla y León ${ }^{43}$ (Artículo 60) optan por el término ratificación de acuerdos y convenios.

e) No se pronuncian sobre la aprobación o autorización de sus respectivas Asambleas Galicia, País Vasco, y Andalucía. Sin embargo, el Artículo 226 del Estatuto de Andalucía prevé que la Comunidad Autónoma puede celebrar convenios con otras Comunidades Autónomas para la gestión y prestación conjunta de servicios propios de las mismas en los supuestos, condiciones y requisitos que determine el Parlamento andaluz, que, en todo caso, dispondrá de mecanismos de control y seguimiento de lo acordado ${ }^{44}$; si bien, varios años después, esta exigencia no se ha cumplido.

la característica - y necesaria — fluidez de los convenios y es, con toda probabilidad, una de las causas del parco número de los concluidos entre Comunidades Autónomas hasta hoy». La Cámara, por el contra «no queda inerme ante una hipotética extralimitación del Gobierno al celebrar un concierto con otra Comunidad Autónoma, pues dicha suscripción, como toda actividad gubernamental, está sujeta al control parlamentario a través de los mecanismos generales que prevé el ordenamiento». CALAFELL FERRÁ, V. J. (2009). «La colaboración en las Islas Baleares», Monográfico sobre Las relaciones de colaboración en los nuevos Estatutos de Autonomía, Revista Jurídica de Castilla y León, núm.19, p. 134.

41 Tras la modificación operada por La Ley Orgánica 2/1999, de 7 de enero. De hecho, los Convenios vienen aprobándose mediante Ley del Parlamento de la Rioja: vid., por ejemplo, la Ley núm. 7/2010, de 29 de septiembre. BO. La Rioja 6 octubre 2010, núm. 123, que Aprueba varios convenios de colaboración con otras Comunidades Autónomas para el establecimiento de programas de actuación conjunta en diversas materiales. Ley 4/2011, de 1 de marzo. BO. La Rioja 7 marzo 2011, núm. 31, Aprueba y autoriza el convenio de colaboración entre Comunidades Autónomas en materia de protección civil y gestión de emergencias.

42 RIDAURA MARTíNEZ, M. . J. (2009). «La Colaboración en la Comunidad Valenciana», Monográfico sobre Las relaciones de colaboración en los nuevos Estatutos de Autonomía, en Revista Jurídica de Castilla y León, núm. 19, pp. 23-65.

43 BELLO PAREDES, S. A., MEDINA ARNAIZ, T. (2009). «La Colaboración en Castilla y León «, Monográfico sobre Las relaciones de colaboración en los nuevos Estatutos de Autonomía, Revista Jurídica de Castilla y León, núm. 19, pp.

44 Este ha sido considerado el rasgo más destacado de la regulación estatutaria, ya que supone conferir mayor centralidad al Parlamento autonómico, BALAGUER CALLEJÓN, F.; CAMARA VILLAR, G., MONTILLA MARTOS, J.A (2007). Estatuto de Andalucía. Novedades respecto del Estatuto de 1981. La nueva configuración del Derecho autonómico de Andalucía. Instituto Andaluz de Administración Pública, p. 155. 
Ciertamente, la autorización previa de las Asambleas autonómicas constituye una exigencia estatutaria que en la mayoría de los Estatutos en que así se prevé, aunque parezca obvio, se cumple; pero, en algunos casos está completamente en desuso. Aunque, dicha intervención parlamentaria se explicaría, cabalmente, en los casos en los que la celebración del convenio intercomunitario supusiera una afectación de la potestad legislativa de les Asambleas autonómicas o una colisión de competencias; estando, entonces, realmente justificada su intervención. Sin embargo, no tiene acomodo apropiado en aquellos casos en los que sólo existe una actividad de relación entre Gobiernos y Administraciones autonómicos en el ámbito de sus competencias para la gestión y prestación de servicios, pues tampoco es una exigencia que, acertadamente, contemple la Constitución ${ }^{45}$. En dichos supuestos, sería suficiente la comunicación a sus respectivas Asambleas para su conocimiento; exigencia que debería asegurarse suficientemente.

3. En tercer lugar, y una vez concluida la fase autonómica de elaboración del convenio, cuando la Constitución delega en los Estatutos la determinación del carácter y los efectos de su comunicación a las Cortes Generales, la mayoría de ellos les confieren la facultad de calificar el acto; concediéndoles un plazo para que éstas pueden oponer reparos u objeciones, en cuyo caso se tramitará como acuerdo de cooperación y, por tanto, requerirá su previa aprobación.

Nuevamente, la ordenación estatutaria es dispar; por lo que podemos clasificar en distintos grupos los Estatutos, en atención al régimen de comunicación de convenios a las Cortes Generales:

a) Sólo contemplan la mera comunicación, señalando un plazo para la entrada en vigor de los convenios los Estatutos valenciano (artículo 59); Vasco, para convenios con territorios históricos (artículo 22.2) y Navarra para el caso de convenios con territorios limítrofes (artículo 70.2 LORAFNA); el de Aragón en su artículo 91 contempla sólo que el Gobierno debe informar a las Cortes de Aragón de la suscripción, así como a las Cortes Generales, a los efectos correspondientes, de los convenios que pueda suscribir para la gestión y prestación de servicios propios de su competencia.

b) Mantienen la necesaria calificación de las Cortes Generales Cantabria (artículo 30), Canarias (artículo 39) Murcia (artículo 19.2), Galicia (artículo 35),

45 Vid., por ejemplo, el Convenio de colaboración entre Comunidades Autónomas en materia de juventud para la coordinación de sus actividades e instalaciones juveniles, suscrito entre diversas Comunidades Autónomas, cuyo alcance material no parece aconsejar el trámite de la aprobación de una Asamblea Autonómica. 
Asturias (artículo 21.1), Castilla-La Mancha (artículo 40.1), Castilla-León (artículo 38).

Al respecto, el Consejo de Estado subrayó que la puesta en conocimiento a las Cortes Generales de los acuerdos o convenios que las Comunidades Autónomas celebren entre si «tiene un sólido fundamento en el deber de lealtad recíproca y en la necesidad de que tanto aquellas como este dispongan de toda la información requerida para llevar a cabo sus funciones en el mantenimiento del orden constitucional» ${ }^{46}$.

Pero, el problema que se plantea, realmente, se centra en determinar si las Cortes tienen o no facultad para poder recalificar un Convenio, habida cuenta de que el texto constitucional sólo prevé, como hemos podido comprobar, la necesaria autorización de los Acuerdos de cooperación. Esto es, cuando las Cortes reciben un Convenio ¿pueden revisarlo para, en su caso, tramitarlo como Acuerdo o sólo pueden darlo por notificado?

En la solución de esta cuestión deben analizarse también los Reglamentos parlamentarios, de cuya ordenación jurídica, a su vez, se desprenden una serie de inconvenientes, que se han subrayado unánimemente por la doctrina: el Reglamento del Senado, en todo caso, plantea la facultad de la Cámara para recalificar el Convenio; independientemente de que los Estatutos de Autonomía hayan previsto o no dicha atribución. En efecto, el Reglamento del Senado (artículo 137) —en desarrollo de los preceptos constitucionales — 74.2 y 145.2 — dispone que, dentro de los cinco días siguientes a su publicación, un Grupo parlamentario o veinticinco Senadores puedan presentar propuestas para que la Cámara decida si el convenio requiere o no autorización. Estas propuestas serán examinadas por la Comisión General de las Comunidades Autónomas, que elevara dictamen al Pleno. En el caso de no presentarse propuesta alguna, el convenio se somete directamente a conocimiento del Pleno ${ }^{47}$. Posteriormente, se remite al Congreso, donde una vez recibida la comunicación, la Mesa la remitirá a la Comisión Constitucional de la Cámara a los efectos previstos en los correspondiente Estatutos de Autonomía (166.1). En ambos casos, si no hubiera acuerdo entre Senado y Congreso, se intentará obtener por una Comisión Mixta compuesta de igual número de Diputados y Senadores. La Comisión presentará un texto, que será votado por ambas Cámaras. Si no se aprueba en la forma establecida, decidirá el Congreso por mayoría absoluta.

\footnotetext{
46 «Informe sobre modificaciones de la Constitución Española», febrero, 2006, p. 200.

47 Sobre el proceder del Senado puede verse, a título de ejemplo, el Boletín Oficial de las Cortes Generales. Senado. X Legislatura. Núm. 85, 19 de julio de 2012.
} 
En relación con la imprecisa y compleja ordenación derivada del texto constitucional, de los Estatutos y de los Reglamentos de las Cortes hay dos corrientes doctrinales al respecto: la mayoritaria sostiene que la comunicación de los Convenios de colaboración a las Cortes es, exclusivamente, una notificación; sin que éstas puedan entrar a analizar su contenido, y, por ende, recalificarlo ${ }^{48}$. Más recientemente, GONZÁLEZ GARCÍA, asumiendo la «torpeza del constituyente» al remitir a los Estatutos de Autonomía el carácter y los efectos de la comunicación de los Convenios de Colaboración, entiende que la Constitución, en su artículo 145.2, al diferenciar entre la comunicación de los Convenios y la autorización de los acuerdos, «implícitamente está reconociendo a las Cortes la capacidad para determinar si lo remitido por las Comunidades Autónomas constituye o no acuerdo de cooperación y, consecuentemente, si necesita su autorización» ${ }^{49}$.

En la práctica, como puede desprenderse de los Boletines de las Cortes, el Senado analiza el contenido del Convenio, con el objeto de proceder o no a su recalificación. De hecho, adviértase la fórmula que se utiliza literalmente: «De conformidad con lo establecido en el artículo 137.2 del Reglamento del Senado, el plazo para la presentación de propuestas para que la Cámara decida si el Convenio remitido necesita o no autorización de las Cortes Generales... " ${ }^{50}$. Además, el Acuerdo de la Junta de Portavoces del Senado, de 20 de mayo de 2008 sobre tramitación de Convenios entre CC.AA. clarifica el proceder de la Cámara.

En cualquier caso, la impugnación del acuerdo de recalificación del convenio podría plantearse a través del Recurso de Amparo Constitucional; al tratarse de

48 En esta dirección se pronuncia SANTOLAYA MACHETTI, P. (1984) al afirmar que «la Constitución parece que está pensando en una simple obligación o carga de «puesta en conocimiento» a las Cortes de la actividad convencional realizada por las Comunidades; sin embargo, los Estatutos, de forma marcadamente antiautonomista, aunque parezca paradójico, han dejado, al regular la naturaleza y efectos de la comunicación, en su inmensa mayoría, en manos de las Cortes Generales una posibilidad de «recalificación» de los convenios como acuerdos, en el sentido de que basta la decisión de las Cortes - y a tenor de muchos de ellos y del artículo 137.2 del Reglamento del Senado, de una sola de las Cámaras - para que el convenio celebrado como tal por dos Comunidades Autónomas se convierta automáticamente en un «acuerdo» con respecto al cual la autorización actúa como requisito de validez», p. 105. La consideración de mera notificación la mantiene, también, GARCÍA COUSO, S. (2004). La participación de las Cortes Generales en los convenios y acuerdos de cooperación entre Comunidades Autónomas, Madrid, Senado. Autora que sostiene que dicha notificación no lleva aparejado ningún proceso de conocimiento por parte de las Cortes, pp. 60 y ss.; CALAFELL, P. 252?

49 GONZÁLEZ GARCÍA, I. (2011). «La facultad de recalificación de las Cortes Generales ex artículo 145.2 ce: una tesis personal», REDC, núm. 91. p. 111

50 Boletín Oficial de las Cortes Generales, Senado, Núm. 5, de 21 de diciembre de 2011. X Legisla- 
un acta interna corporis (artículo 42 LOTC). Mientras que, en el caso de que las CC.AA. hubieran acudido indebidamente a la vía del Convenio de Colaboración, debiendo tratarse — por su objeto- de un Acuerdo de Cooperación, el Gobierno podría impugnarlo ante el Tribunal Constitucional por la vía de la impugnación de las disposiciones y resoluciones adoptadas por los órganos de las Comunidades Autónomas (artículo 161.2).

En relación con los acuerdos de cooperación entre las Comunidades Autónomas, para los que se requiere la previa autorización de las Cortes Generales, se sigue el procedimiento legislativo con una serie de especialidades (artículo $138 \mathrm{RS})^{51}$. Dicha autorización opera como requisito de validez del Acuerdo; un claro ejemplo de ello es la declaración de nulidad de la resolución del Presidente de la Generalidad de Cataluña que aprueba el acuerdo, suscrito con el Presidente del Consejo Regional de Murcia, y como consecuencia la nulidad del mismo, por falta de un requisito constitucional necesario para su validez: la autorización de las Cortes Generales (STC 44/1986).

4. Por último, los Estatutos de Autonomía sujetan la entrada en vigor de los convenios de colaboración a la notificación de los mismos a las Cortes Generales. La mayoría de los textos disponen la entrada en vigor del convenio a los 30 días dicha comunicación, siempre y cuando éstas no hubieran formulado objeciones $^{52}$; aunque, algunos Estatutos reformados recientemente han ampliado el plazo para la entrada en vigor del convenio: es el caso de Cataluña (artículo 178),

51 La Comisión General de las Comunidades Autónomas elevará al Pleno dictamen en el que se proponga de forma razonada la concesión de la autorización, su denegación o su otorgamiento con determinadas condiciones. Una vez aprobado el dictamen por el Pleno del Senado, el Presidente dará traslado del mismo al Congreso de los Diputados. Recibida una comunicación del Senado que conceda o deniegue la autorización para celebrar un acuerdo de cooperación entre Comunidades Autónomas, en los supuestos no regulados en el apartado anterior, la Mesa decidirá su remisión a la Comisión Constitucional para que emita el correspondiente dictamen, que será discutido en el Pleno de acuerdo con el procedimiento establecido en este Reglamento para los debates de totalidad (166.2) Si el acuerdo fuera coincidente con el del Senado, el Presidente del Congreso lo comunicará a los Presidentes de las Comunidades afectadas. Si fuera contrario, lo hará saber al Presidente del Senado a efectos de nombramiento de la Comisión Mixta prevista en el artículo 74.2 de la Constitución, la cual presentará un texto que será sometido a votación de ambas Cámaras. - se puede solicitar a las Comunidades Autónomas afectadas que remitan información y alegaciones así como que designen, si lo desean, a sus representantes en el procedimiento (artículo 139 RS). El texto elaborado por la Comisión Mixta será sometido directamente a la deliberación y votación del Senado. De su resultado se dará cuenta al Congreso de los Diputados, y Si no se aprueba en la forma establecida, decidirá el Congreso por mayoría absoluta. (166.3).

52 Aragón (artículo 40), Asturias (artículo 21), Cantabria (artículo 31), Castilla-La Mancha (artículo 40), Castilla y León (artículo 38), Extremadura, cuyo artículo 65 se refiere concretamen- 
de las Islas Baleares (artículo 118), y el de Andalucía ${ }^{53}$ (artículo 226.2); Estatuto que atribuye la función de comunicar a las Cortes Generales la celebración de convenios al propio Parlamento.

En este caso, las particularidades se plantean en tres Estatutos de Autonomía: en primer lugar, el de Aragón guarda silencio sobre este extremo, al disponer que el Gobierno debe informar a las Cortes de Aragón de la suscripción del Convenio en el plazo de un mes a contar desde el día de la firma, debiendo, igualmente, informar a las Cortes Generales a los efectos correspondientes (artículo 91); por lo que parece desvincular la entrada en vigor del convenio de la comunicación a las Cortes. En segundo lugar, el de Murcia establece que «Transcurridos treinta días desde la recepción de la comunicación por las Cortes sin que ninguna de las Cámaras haya objetado la conclusión del convenio o, en todo caso, luego de obtenida la autorización de las Cortes, se procederá a la publicación de aquél en el «Boletín Oficial de la Región de Murcia» y en el «Boletín Oficial del Estado», entrando en vigor a tenor de lo que el mismo disponga» (artículo 19). Por último, el de la Comunidad Valenciana dispone los convenios que entrarán en vigor a los 30 días de su publicación, tras su aprobación por las Cortes Valencianas y su comunicación a las Cortes Generales. Esta ordenación nos plantea serios interrogantes, ya que, al sujetar la entrada en vigor del Convenio a los 30 días de su publicación, la primera cuestión que hemos de resolver es qué validez tienen los Convenios que, pese al mandato estatutario, no se tramitan ante las Cortes Valencianas para su aprobación, ya que dicha exigencia debería operar como un requisito de validez. Lo que nos conduce a cuestionar si es posible su comunicación a las Cortes Generales, si no cumple con este requisito y, por tanto, no se publica oficialmente antes de dicha comunicación.

Otra duda que debemos plantearnos es la de la validez de aquellos Convenios que reiteradamente, pese a la exigencia, en este caso constitucional, de la comunicación a las Cortes Generales, se han suscrito entre las CC.AA. sin que se hubiera cumplido este requisito; lo que provoca inseguridad jurídica.

En definitiva, el marco jurídico analizado ha sido calificado, con gran acierto, como «excesivamente confuso, riguroso y, en cualquier caso, inadecuado para fomentar las relaciones entre CC.AA.» ${ }^{54}$. Máxime cuando una ordenación jurí-

te a recomendaciones no vinculantes de las Cortes Generales, Galicia (artículo 35), Madrid (artículo 31), Navarra (artículo 70), Rioja (artículo 14).

53 FERNÁNDEZ ALLES, J.J. (2007). «Las relaciones intergubernamentales en el nuevo estatuto de autonomía de Andalucía», Revista de Derecho Político, núm. 70, pp.179-221.

54 GARCÍA MORALES, M. J J. (2009). «La colaboración a examen: Retos y riesgos de las relaciones intergubernamentales en el Estado autonómico», Revista Española de Derecho Constitucional, núm. 86, p. 56. «De este modo, se configura un procedimiento cooperativo excesivamente 
dica tan heterogénea dificulta la suscripción de Convenios entre CC.AA. Por ello, sorprende que las recientes reformas estatutarias no hayan servido para proceder a una regulación más coherente y racional del régimen jurídico de los Convenios y Acuerdos de colaboración. Hubiera sido deseable, pues, que en un tema de tanta relevancia como es la práctica convencional se hubieran regulado claramente estos instrumentos de colaboración, soslayando los obstáculos tan palmarios en su ordenación jurídica.

\section{EVIDENCIA DE LA PRÁCTICA EMPÍRICA EN MATERIA DE COLABORACIÓN HORIZONTAL ENTRE CC.AA.}

\section{Etapas en la colaboración horizontal}

Como podremos apreciar a continuación, en la práctica empírica de la colaboración entre Comunidades Autónomas podemos distinguir cuatro etapas:

\section{1. ${ }^{a} \quad$ Escasa o nula colaboración}

Esta etapa, que comprendería las primeras Legislaturas, se caracteriza por una inexistente o escasa colaboración entre las Comunidades Autónomas; lo que se explica al coincidir con los primeros años de andadura constitucional, y con la constitución de cada Comunidad y la articulación de su estructura políticoadministrativa. Por ello, es explicable el escaso número de convenios o acuerdos de colaboración, y el elevado número de convenios verticales; ya que como hemos advertido con anterioridad, éstos últimos se revelaron como los instrumentos idóneos para el traspaso competencial y de los recursos correspondientes a las competencias transferidas.

2. $\quad$ Mayor colaboración, pero, sobre todo, sumergida o poco visible

En la segunda etapa se advierte un leve estreno de los convenios y acuerdos de colaboración, pero todavía son poco significativos. La causa, fundamentalmen-

rígido, en donde se confiere a las asambleas legislativas, tanto a las autonómicas como a las Cortes Generales, un protagonismo que no casa en absoluto ni con la naturaleza intergubernamental del fenómeno regulado CARMONA CONTRERAS, A. (2009). »La colaboración en Andalucía» Monográfico sobre Las relaciones de colaboración en los nuevos Estatutos de Autonomía, Revista Jurídica de Castilla y León, núm.19, p. 177. 
te, además de la necesaria consolidación y afirmación de la estructura territorial, se centra en las dificultades del marco normativo para articular la colaboración institucional entre CC.AA. Ahora bien, en esta etapa emerge toda una red de relaciones interautonómicas sumergidas o poco visibles: las reuniones de consejeros sectoriales, las relaciones administrativas cotidianas entre funcionarios, las cumbres multilaterales de partidos, entre otras, que revelan la existencia de un entramado real de colaboración, sorteando los obstáculos de los instrumentos previstos en la Constitución y en los Estatutos ${ }^{55}$.

3. ${ }^{a} \quad$ Drástico incremento de los de convenios de colaboración y nacimiento de nuevos instrumentos

Una tercera etapa, en la que, eludiendo el encorsetado marco constitucional y estatutario, se advierte un incremento muy significativo de los Convenios horizontales. Y es que, pese a que los obstáculos constitucionales no han desaparecido, y pese a que los Estatutos de Autonomía reformados a partir del año 2004 han introducido cambios poco relevantes en este ámbito, la práctica de la colaboración horizontal se ha visto fuertemente impulsada en los últimos años. Exponencial de la consciencia comunitaria de los beneficios de la colaboración horizontal es el elevado número de convenios suscritos para la prestación de servicios públicos. Además, coincidiendo con dichas reformas estatutarias, en algunas CC.AA., y con el objeto de profundizar en su desarrollo se han instituido los Encuentros entre Comunidades Autónomas para el desarrollo de sus Estatutos de Autonomía, a raíz de los cuales se ha creado la Conferencia de los Gobiernos de las Comunidades Autónomas.

4. ${ }^{a} \quad$ Colaboración convencional mantenida; pero diluida por los efectos de la crisis económica

Finalmente, en la actualidad, la colaboración horizontal viene caracterizada por una paradójica situación en la que, perviviendo un rico entramado convencional, fruto de la reciente etapa de apogeo de estas técnicas de colaboración, al hilo de la consolidación competencial de las CC.AA., se han desactivado los foros de colaboración de reciente creación; como consecuencia de una paralización de la actividad competencial autonómica, ante los devastadores efectos de la crisis económica, que las lleva a centrarse en reducir a toda costa sus elevadas cifras de déficit.

55 Un estudio con mayor detalle lo realiza COLINO, C. (2010), ob. cit., pp. 351 y ss. 


\section{La materialización de la colaboración entre CC.AA.}

Los datos que aportamos a continuación revelan el inicio y la progresiva evolución de las relaciones intercomunitarias. Conviene advertir, previamente, que en muy pocos casos encontramos Registros ${ }^{56}$ de Convenios horizontales con la necesaria publicidad, y, por tanto, de fácil accesibilidad: el Registro catalán es el más completo, accesible y sistemático, seguido del Gallego, Aragonés y el de Castilla-León ${ }^{57}$; práctica que debería extenderse en las demás Comunidades Autónomas, conviniendo en la adopción de criterios más uniformes para su tratamiento. En consecuencia, los datos que se aportan se corresponden con los convenios y acuerdos oficialmente tramitados en Congreso y Senado; pues, cumpliendo con las exigencias del artículo 145.2 de la Constitución y de su posterior desarrollo estatutario, tal y como hemos visto, dichos instrumentos deben comunicarse a las Cortes Generales.

56 Más recientemente, vid. Decreto 52/2005, de 5 de abril, de creación y regulación del Registro de convenios de colaboración y cooperación, modificado por el Decreto 322/2006, de 22 de agosto. Decreto 126/2006, de 20 de julio, por el cual se regula el Registro de Convenios de la Xunta de Galicia. Decreto 315/2007, de 27 de diciembre, de Registro General de Convenios de la Administración de la Junta de Castilla-La Mancha. El Decreto 49/2010, del Gobierno Balear, de 13 de mayo, de creación y regulación del Registro de convenios de colaboración con el Estado y las Comunidades Autónomas y el Registro de acuerdos de colaboración con Administraciones y entidades públicas extranjeras. Decreto 30/2010, de 19 de agosto, por el cual se regula el Registro General de Convenios de la Administración de la Comunidad de Castilla y León. Decreto Foral 43/2010, de 9 de agosto por el que se regula el Registro de convenios y acuerdos de la Administración de la Comunidad Foral de Navarra. Decreto 160/2010, de 14 de septiembre, del Presidente de Canarias, de organización y funcionamiento del Registro de convenios de colaboración con el Estado y las Comunidades Autónomas. Decreto 57/2012, de 7 de marzo, del Gobierno de Aragón, por el que se regula el Registro General de Convenios de la Comunidad Autónoma de Aragón.

57 Los cuatro cuentan con acceso electrónico a las bases de Convenios. 
Tabla 1. Número de Convenios, Acuerdos y Protocolos de colaboración, tramitados en las Cortes Generales, por Legislaturas

\begin{tabular}{|c|c|c|c|c|}
\hline LEGISLATURA & CONVENIOS & ACUERDOS & PROTOCOLOS & TOTAL \\
\hline I & 0 & 0 & 0 & 0 \\
\hline II & 1 & 0 & 0 & 1 \\
\hline III & 2 & 0 & 0 & 2 \\
\hline IV & 0 & 0 & 2 & 2 \\
\hline V & 1 & 1 & 0 & 2 \\
\hline VI & $12^{58}$ & 1 & 1 & 14 \\
\hline VII & 3 & 0 & 1 & 4 \\
\hline VIII & 10 & $1^{59}$ & 0 & 11 \\
\hline IX & 32 & 0 & 4 & 36 \\
\hline X $^{60}$ & 8 & 0 & 0 & 8 \\
\hline
\end{tabular}

Elaboración propia, a partir de los Datos del Congreso de los Diputados y del Senado.

Gráfico 1. Evolución de los Convenios, Acuerdos y Protocolos de colaboración, tramitados en las Cortes Generales, por Legislaturas

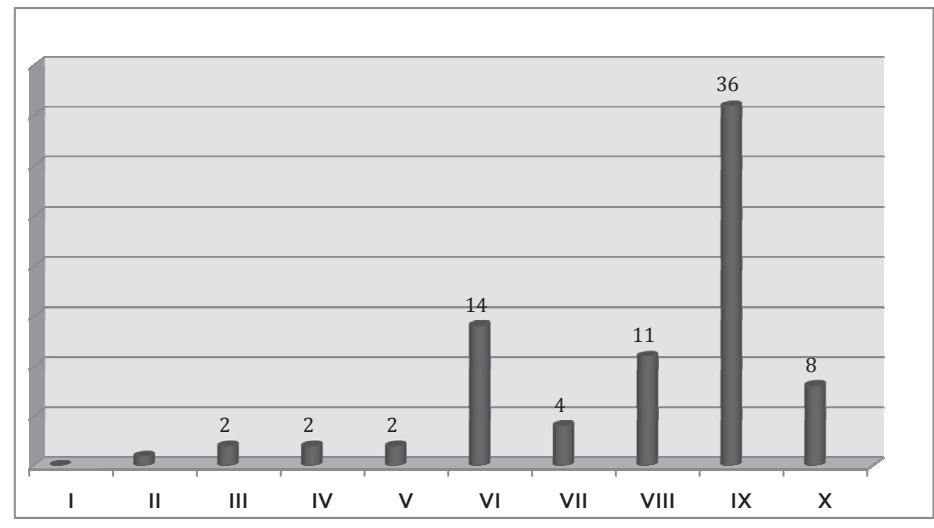

Elaboración propia, a partir de los Datos del Congreso de los Diputados y del Senado.

58 El Convenio Marco de Colaboración Transregional entre la Junta de Andalucía, la Generalidad Valenciana, la Diputación de Barcelona, la Comunidad Autónoma de la Región de Murcia y el Consejo Insular de Mallorca. (592/000011) inadmitido a trámite en términos absolutos.

59 Aparece el Acuerdo de cooperación en materia de protección civil entre la Comunidad Autónoma de Galicia y la Comunidad Autónoma del Principado de Asturias, sin embargo, se ha tramitado como Convenio de colaboración. Denominación que, como indica GARCIA MORALES, M. ${ }^{a}$ J. (2008), le dieron las partes, pero no se «corresponde con la naturaleza de sus cláusulas similares - e, incluso, más genéricas, que la de otros textos en esta materia que han pasado por la Cámara como meros convenios de colaboración». Así se advirtió por el Dictamen de la Comisión General de Comunidades Autónomas. «Relaciones de Colaboración con las Comunidades Autónomas», Informe Comunidades Autónomas, 2007, p. 186.

60 Datos hasta finales de 2012. Legislatura que comenzó el 13 de diciembre de 2011. 
Verdaderamente, estos datos oficiales del Congreso y del Senado no reflejan la auténtica realidad convencional, ya que las Comunidades Autónomas no siempre cumplen con el mandato constitucional de la comunicación a las Cortes Generales; encontrándonos con convenios que han estado o siguen en vigor, que figuran en Registros autonómicos, poco visibles y poco accesibles, pero de cuya suscripción no se ha dado cuenta a las Cortes Generales.

Por otro lado, si se observamos los datos ofrecidos por los Registros de Convenios de algunas CC.AA. podrá advertirse cómo en ellos figuras, con la denominación «Convenio de Colaboración», instrumentos de carácter interadministrativo en cuyas sus cláusulas se especifica que tienen un régimen jurídico-administrativo, siéndoles de aplicación la Ley 30/1992, de 26 de noviembre, pero que no se tramitan como Convenios de colaboración conforme artículo 145 de la $\mathrm{CE}^{61}$. Lo que revela una deficiente calificación jurídica de dichos actos.

Además, conviene señalar que se ha convertido en práctica habitual comunicar a las Cortes la suscripción de algunos Protocolos, pese a que en este caso no hay una exigencia ni constitucional ni estatutaria ${ }^{62}$. Dicha comunicación, en los pocos casos en que se produce, es loable a efectos informativos, y debería generalizarse para ofrecer parámetros más certeros de la colaboración real. El problema se plantea cuando de la actividad parlamentaria se desprende que también éstos se califican al igual que los convenios y los acuerdos; lo que supone dotarles de una rigidez no prevista normativamente.

61 En este caso podríamos hablar de un número elevado; sirvan de ejemplo los siguientes: Convenio de colaboración con la Junta de Comunidades de Castilla-La Mancha para la realización del Programa de actividades complementarias y viajes educativos en los centros escolares, a través de las rutas a realizar en Cantavieja, Teruel, Daroca y Sos del Rey Católico y en Castilla la Mancha (Ruta de don Quijote) durante el curso escolar 2009-2010.

62 Antes al contrario, ya que el Tribunal Constitucional advirtió en la Sentencia 44/1986 que las exigencias constitucional y estatutarias son aplicables a los Convenios; pero no se extienden a supuestos que no merezcan esa calificación jurídica, como pudieran ser declaraciones conjuntas de intenciones, o propósitos sin contenido vinculante, o la mera exposición de directrices o líneas de actuación. 
Gráfico 2. Porcentaje de Convenios, Acuerdos y Protocolos de colaboración, tramitados en las Cortes Generales

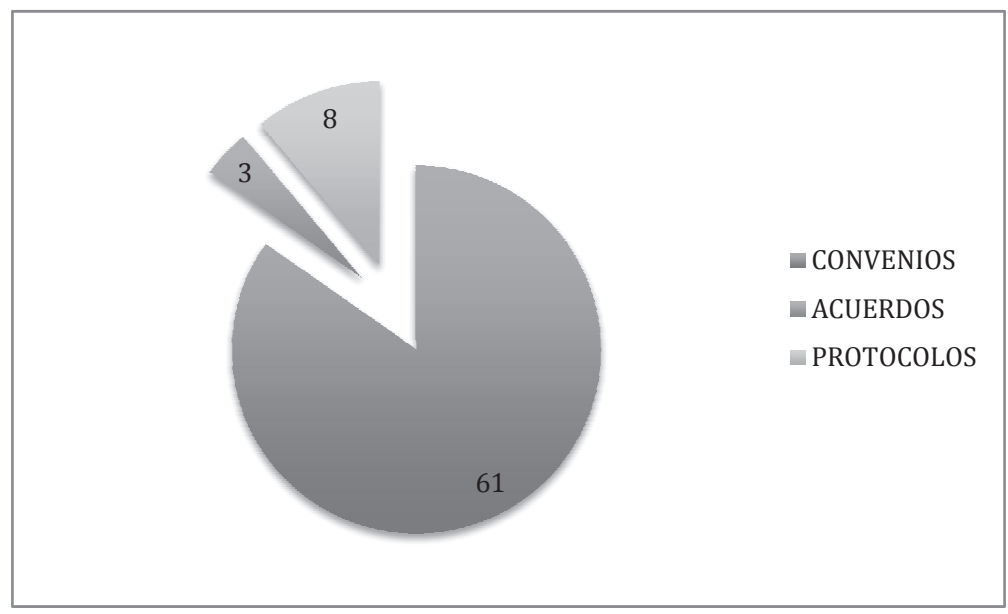

Elaboración propia, a partir de los Datos del Congreso de los Diputados y del Senado.

Los ámbitos de colaboración se concretan en actuaciones conjuntas, entre otras, en materia de trasporte público; colaboración sanitaria en materia de trasplante renal, hepático, cardiaco y pulmonar; urgencias y emergencias en zonas limítrofes; fusión de registros; prevención y extinción de incendios forestales, coordinación de centros de acogida a las mujeres víctimas de violencia de género; reconocimiento recíproco de licencias de caza y pesca; impulso de actuaciones conjuntas en materia turística; intercambio de información sobre la identidad de personas registradas en parejas de hecho. Esto es, ámbitos de colaboración que pueden implicar una gestión más eficaz de los servicios públicos, acortando distancias entre Administración y ciudadanía ${ }^{63}$; lo implica una mayor grado de institucionalización del modelo autonómico.

En un principio, los Convenios se suscribían entre Comunidades limítrofes, generalmente, para la prestación de servicios comunes. La siguiente tabla ofrece, siempre con los datos oficiales sobre los que estamos trabajando, la mayor o menor tendencia de las Comunidades Autónomas en la práctica convencional.

63 GARCÍA MORALES, M. ${ }^{a}$ J. (2008) ob. cit, p. 15, Asimismo, MATIA PORTILla apunta la virtualidad de las relaciones intercomunitarias en aras de una mayor eficiencia «en el funcionamiento del Estado español en el marco de la Unión Europea», MATIA PORTILLA, J. (2011). «La cooperación horizontal: un impulso tan necesario como esperado», Revista Jurídica de Castilla y León, núm. 23, p. 142. 
Gráfico 3. Frecuencia de las CC.AA. en la práctica convencional

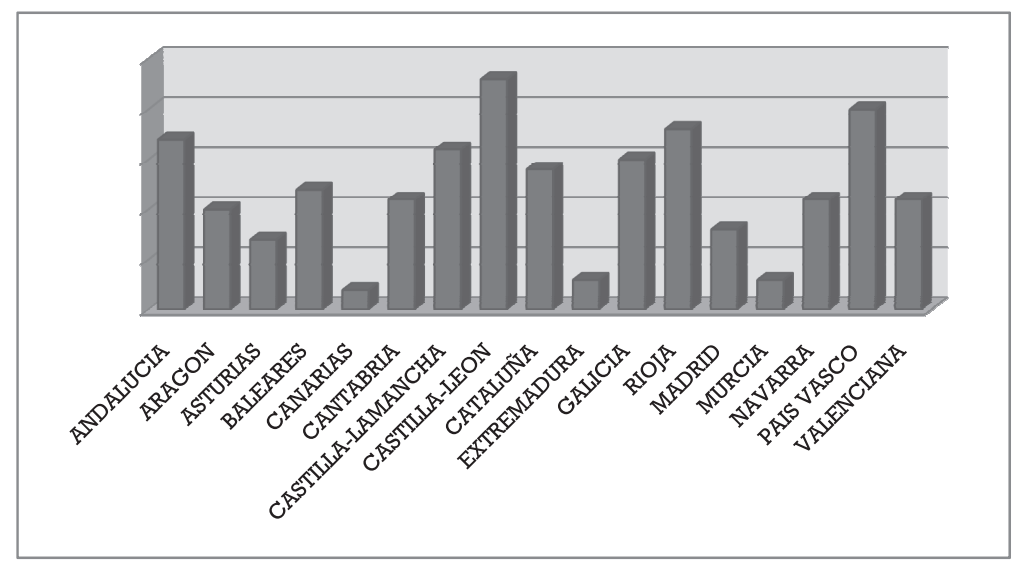

Elaboración propia, a parir de los datos obtenidos del Congreso de los Diputados y del Senado.

\section{La constitución de nuevos instrumentos de colaboración horizontal}

A partir del año 2008 las seis ${ }^{64}$ Comunidades Autónomas que reformaron sus Estatutos de Autonomía acordaron reunirse periódicamente con el objetivo de impulsar el desarrollo y la coordinación de sus competencias. Con este objeto crearon el foro Encuentros entre Comunidades Autónomas para el desarrollo de sus Estatutos de Autonomía.

Dichos Encuentros han impreso un nuevo carácter a la colaboración intercomunitaria, resultando de los mismos tanto la suscripción de un elevado número de Convenios de Colaboración, como la vigorización de los Convenios de suscripción generalizada; tan exiguos hasta el momento: sirva de ejemplo, el Convenio de Colaboración entre CC.AA. en materia de protección civil y gestión de emergencias suscrito por 12 CC.AA. ${ }^{65}$

64 Las primeras CC.AA. que promovieron los encuentros fueron Andalucía, Aragón, Castilla y León, Cataluña, Comunidad Valenciana y las Islas Baleares. Desde el año 2008, se han celebrado ocho Encuentros en las ciudades de I. ${ }^{\circ}$ Zaragoza (9 de julio de 2008); II. ${ }^{\circ}$ Sevilla (20 de octubre de 2008); III. ${ }^{\circ}$ Valladolid (23 de febrero de 2009); IV. ${ }^{\circ}$ Valencia (29 de junio de 2009); V. ${ }^{\circ}$ Barcelona (16 de noviembre de 2009), se formalizó el acuerdo para que La Rioja y CastillaLa Mancha se incorporaran como nuevos miembros del foro; VI. ${ }^{\circ}$ Palma (8 de marzo de 2010) se formalizó el acuerdo para que Galicia se incorporara como nuevo miembro del foro Galicia; VII. ${ }^{\circ}$ Logroño (5 de julio de 2010); VIII. ${ }^{\circ}$ Santiago de Compostela (25 de octubre de 2010).

65 Aragón, Comunidad Valenciana, La Rioja, País Vasco, Baleares, Castilla-León, Andalucía, Extremadura, Galicia, Cantabria, Cataluña y Castilla-La Mancha. 
Los Encuentros entre CC.AA. han servido, también, de plataforma para la adopción de una serie de acuerdos sobre temas de interés: por ejemplo, el Acuerdo sobre la necesidad de reforma de la norma estatal reguladora del orden de precedencias de autoridades; la Declaración sobre la incidencia de la fijación de bases estatales en el sistema de distribución de competencias; el Acuerdo sobre participación en el nombramiento de miembros del consejo económico y social y del consejo de administración de la corporación Radio Televisión Española; o la Declaración sobre la función constitucional del Senado.

Sobre todo, la evidencia empírica de los resultados tan favorables obtenidos con el afianzamiento de la colaboración intercomunitaria condujeron a que en el VIII Encuentro de Comunidades Autónomas, celebrado en Santiago de Compostela, se acordara su institucionalización mediante la constitución de Conferencia de los Gobiernos de las Comunidades Autónomas ${ }^{66}$, con la finalidad de promover la cooperación y la colaboración política y administrativa entre ellas. La Primera Conferencia de Comunidades se celebró en Santander el 21 de marzo de 2011; a la que progresivamente se han ido sumando la mayoría de las CC.AA ${ }^{67}$. Esta institucionalización de las relaciones intercomunitarias se ha completado con la dotación de normas de organización y funcionamiento, estableciéndose como Sede para la Secretaría permanente la Comunidad Autónoma de Aragón.

La actual situación de crisis económica, sin embargo, determina la ralentización de estas herramientas de colaboración, que tanto han coadyuvado al cabal funcionamiento de la organización territorial del Estado.

Title:

THE HORIZONTAL COLLABORATION AMONG AUTONOMOUS COMUNITIES: LEGAL FRAMEWORK, RUNNING AND WORKING

\section{Resumen:}

El trabajo tiene como objeto el estudio de las relaciones de colaboración entre Comunidades Autónomas en España, como paradigma de Estado descentralizado. Analizándose la progresiva evolución de

66 Creación por la que ya abogaban AJA, E. y GARCIA MORALES, M. J. (2000). «Las Relaciones entre Comunidades Autónomas: problemas y perspectivas», Informe Comunidades Autónomas 2000, Instituto de Derecho Público, Barcelona, pp. 661-662.

${ }^{67}$ Está integrada por las Comunidades Autónomas Cantabria, Asturias, Cataluña, Navarra, Galicia, Andalucía, La Rioja, Murcia, Comunidad Valenciana, Aragón, Canarias, Castilla-La Mancha, Extremadura, Baleares, Madrid y Castilla y León. Con mayor detalle vid. el trabajo de RUIZ GONZÁLEZ, J. G. (2012). «La cooperación intergubernamental en el estado autonómico: situación y perspectivas», REAF, 15, pp. 314 y ss. 
dichas relaciones, y, paralelamente, la gradual implantación de los instrumentos jurídicos e institucionales que han vehiculizado la colaboración horizontal. Proceso que cristalizó en la generalización de los mismos, en un marco de afirmación de la estructura territorial descentralizada de nuestro Estado, y que ha permitido dotar de mayor normalidad a las relaciones intercomunitarias; ralentizadas, sin embargo, en la actualidad, por la crisis económica.

\begin{abstract}
:
The focus of this article is the relations between the Comunidades $A u$ tónomas in Spain, as a paradigm of a decentralized State. The author analyses the progressive evolution of this relations, including the gradual development of the institutional and legal instruments that have articulated the horizontal collaboration between the regions. The generalization of these instruments consolidated the decentralized territorial structure of Spain and contributed to the normalization of the relations between the different regions, although this process has been negatively affected by the current economic crisis.
\end{abstract}

\title{
Palabras clave:
}

Relaciones horizontales, relaciones entre Comunidades Autónomas, nuevos impulsos en la colaboración; funcionamiento de la colaboración horizontal.

\section{Key words:}

Horizontal relations; relationship among the autonomous communities; a new drive in the cooperation; running of cooperation horizontal. 
